\title{
Association of Trichorhinophalangeal Syndrome and Loose Anagen Syndrome: A Case Report
}

\author{
Sandra Cecilia García-García ${ }^{a}$ Maira Elizabeth Herz-Ruelas a
}

Minerva Gomez-Flores ${ }^{a} \quad$ Norma Elizabeth Vázquez-Herrera ${ }^{b} \quad$ Cosimo Miscialic Antonella Tosti $^{d}$ Sonia Chavez-Alvarez ${ }^{a} \quad$ Jorge Ocampo-Candiania

Alejandra Villarreal-Martinez ${ }^{a}$

a Dermatology Department, Hospital Universitario “Dr. José Eleuterio González,” Universidad Autónoma de Nuevo

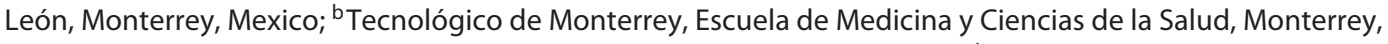

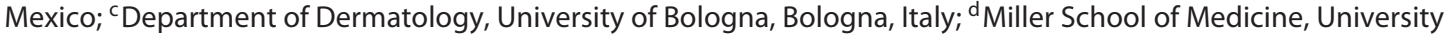
of Miami, Miami, FL, USA

\section{Established Facts}

- Rectangular black granular structures are unique trichoscopic features of loose anagen syndrome (LAS).

- An association between LAS and trichorhinophalangeal syndrome (TRPS) has been previously suggested.

\section{Novel Insights}

- This case represents the association of TRPS and LAS in a family.

- The black rectangular trichoscopic structures correspond to empty anagen follicles.

\section{Keywords}

Trichorhinophalangeal syndrome - Loose anagen syndrome · Trichoscopy · Trichogram · Pull-test

\section{Abstract \\ Trichorhinophalangeal syndrome (TRPS) is an autosomal dominant disease characterized by trichologic, craniofacial, and musculoskeletal abnormalities. Predominant clinical features include a pear-shaped nose with bulbous tip, long}

philtrum, protruding ears, and sparse hair on both the scalp and the lateral third of the eyebrows. Cone-shaped epiphyses are a common radiographic finding. Loose anagen syndrome (LAS) is a sporadic or autosomal dominant condition due to abnormalities in the hair's anchoring mechanism. It mostly affects children, who usually have reduced hair length, as well as hair that is easily plucked without pain. Recent contributions regarding trichoscopic findings of LAS have been made, describing rectangular black granular structures as a typical feature. An association between TRPS karger@karger.com

www.karger.com/sad

Karger $\stackrel{2}{\circ}$
(C) 2020 S. Karger AG, Basel

(n)
Alejandra Villarreal-Martinez, MD

Hospital Universitario “Dr. José Eleuterio González"

Av. Francisco I. Madero Pte s/n y Av. Gonzalitos s/n, Col. Mitras Centro

Monterrey 64460 (Mexico)

dravillarrealmtz@yahoo.com.mx 
and LAS has been mentioned by hair experts, but no reports documenting this have been published. This case demonstrates the co-existence of both conditions in a patient with characteristic phenotypic traits of TRPS and LAS.

(c) 2020 S. Karger AG, Basel

\section{Introduction}

Trichorhinophalangeal syndrome (TRPS), first described by Giedion in 1966, is a genetic disease with an autosomal dominant pattern. It is characterized by a triad of trichologic, craniofacial, and musculoskeletal abnormalities [1]. Three types of TRPS have been described in the literature (I, II, and III) [2-5]. A defective TRPS1 gene is responsible of the typical features, such as a pear-shaped nose with bulbous tip, long philtrum, protruding ears, maxillary prognathism with mandibular hypoplasia, and sparse hair on both the scalp and the lateral third of the eyebrows $[1,6]$. Common musculoskeletal findings include brachydactyly and cone-shaped epiphyses [7]. The most common is type I, and type II includes affection of both TRPS1 and EXT1 genes and presents with cartilaginous exostoses, microcephaly, and mental retardation [3]. Type III is similar to type I, except for more severe brachydactyly and short stature $[2,6]$.

On the other hand, loose anagen syndrome (LAS) is a benign and self-limiting condition. It is either sporadic or autosomal dominant, due to abnormalities in the hair's anchoring mechanism. It mostly affects children, who usually present with a reduced hair length, as well as easily pluckable hair without pain [8]. A possible association between LAS and TRPS has been previously mentioned in textbooks and review papers $[6,9]$ but no reports confirming its co-existence have been published.

\section{Case Report}

A 6-year-old girl presented to the outpatient clinic complaining that her hair did not grow. She had never had a haircut since her birth. Physical examination of her scalp showed fine and short hair (with length above the shoulders). Trichoscopy revealed the presence of hair thinning and some isolated black granular rectangular structures (Fig. 1). Upon physical examination, she exhibited a characteristic facies, consisting of frontal broadening, recession of frontal hairline, decreased hair density in the distal third of both eyebrows, an elongated nose philtrum with a broad, pear-shaped nasal tip, prominent ears with low implantation, thin lips with a horizontal smile, and mandibular hypoplasia. She also presented dental malocclusion, onychodystrophy, and brachydactyly of the first toes (Fig. 2).

Trichorhinophalangeal Syndrome and Loose Anagen Syndrome
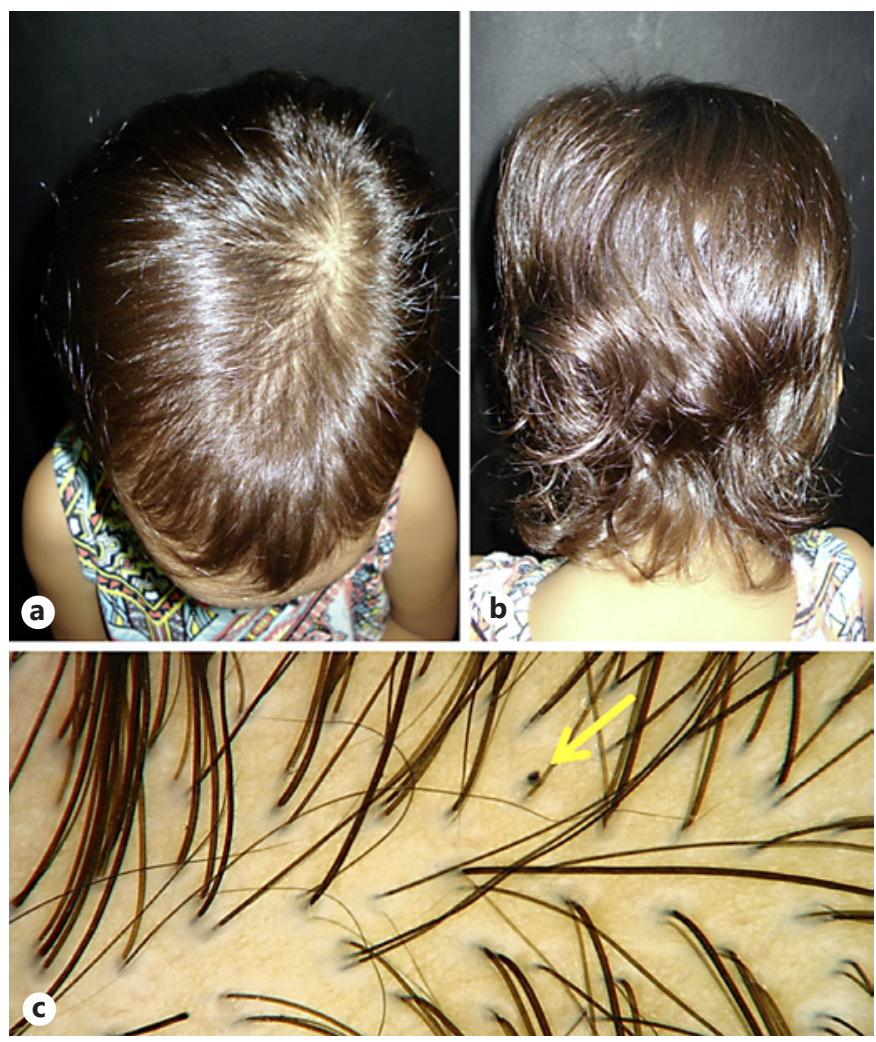

Fig. 1. a, b Physical examination of the scalp showing fine and short hair. c Hair thinning and black granular rectangular structures were seen on trichoscopy.

The family history revealed that the patient's father, grandfather, and a paternal uncle had a similar phenotype. Her 27-yearold father had similar facial characteristics, severe hair thinning, and alopecic areas resembling androgenetic alopecia, with similar trichoscopic findings. He also had brachyonychia of the thumbs ("racket nails"), a more pronounced brachydactyly, as well as deviation of the toes (Fig. 3).

The girl's hair pull-test was positive, and her trichogram had more than $70 \%$ of hairs in the anagen phase, with disruption of the hair sheaths, as well as distal hair fractures. X-rays revealed a delay in osseous age, and cone-shaped ephiphyses (Fig. 4). Histopathology of the trichoscopic black granular rectangular structures observed in the father's scalp showed lamellar fibroplasia around anagen follicles, as well as desquamation and rupture of the inner hair root sheath (Fig. 5).

\section{Discussion}

TRPS is a rare, genetic, autosomal dominant condition characterized by craniofacial, musculoskeletal, and pilar abnormalities [1]. The first early descriptions are attributed to Klingmüller in 1956, and Van der Werff ten Bosh in 1959, but it was not until the year 1966 that An-

Skin Appendage Disord 2020;6:162-167 


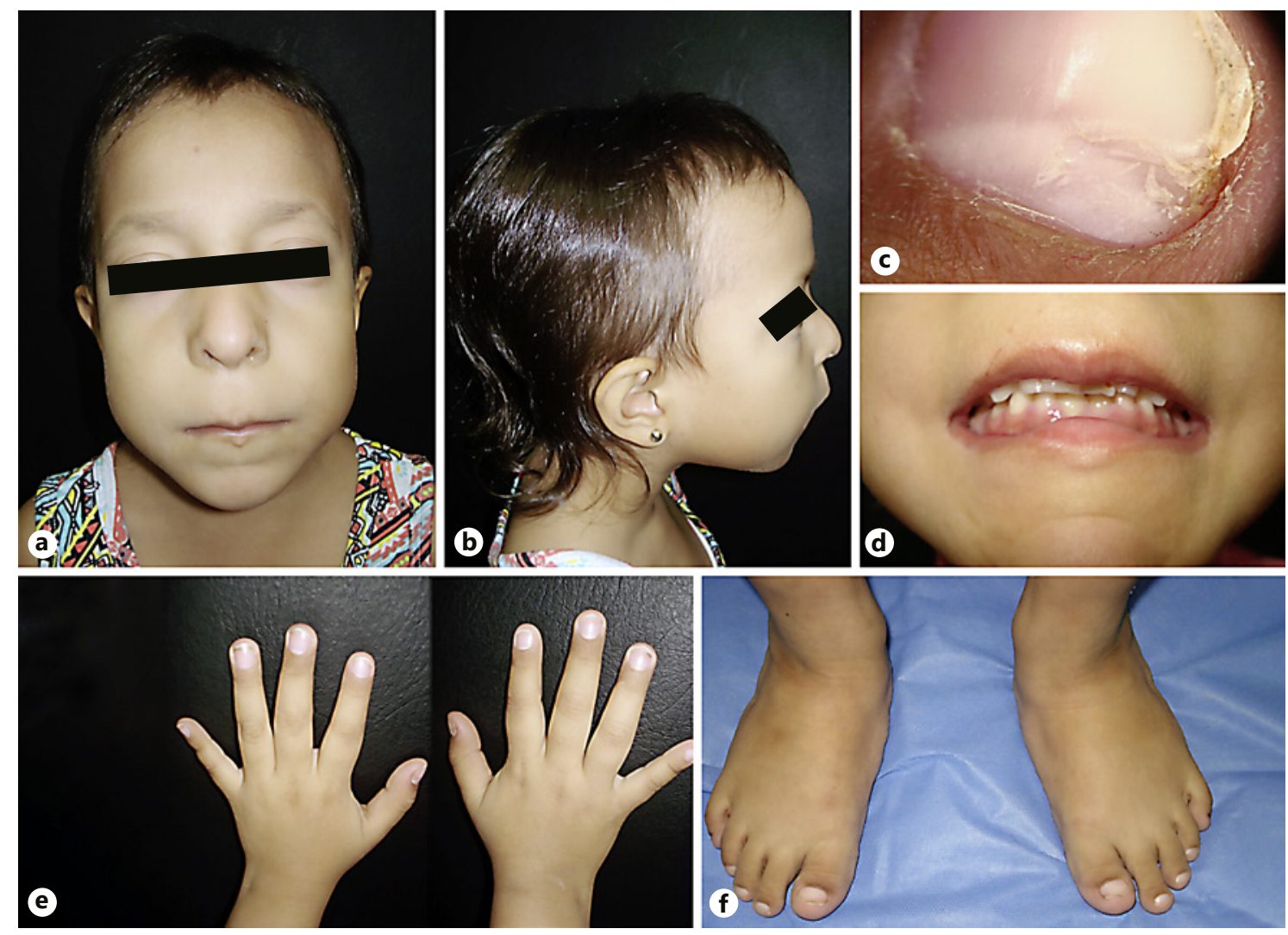

Fig. 2. Physical examination revealed characteristic findings. a, b Typical phenotype. c Onychodystrophy. d Horizontal smile. e Widening of the 4 th and 5 th fingers of both hands. $\mathbf{f}$ Brachydactyly of the first toes.

dres Giedion reported several cases, some of them with exostoses and intellectual disability. He decided to name the entity tricho-rhino-phalangeal syndrome (TRPS). Later, in 1969, Leonard Langer described affected individuals with similar characteristics, developmental delay, and multiple exostoses [10]. Three types of TRPS have been described in the literature (I, II, and III), all related to alterations in the TRPS1 gene [2-5]. Even when they all share the typical phenotype, TRPS I is characterized by a normal development and absence of exostoses, TRPS II or Langer-Giedon syndrome presents with exostoses and intellectual disability due to a contiguous gene deletion involving the EXT1 gene, and TRPS III presents with a marked growth impairment and brachydactyly [10].

In 2015, the largest series of patients with TRPS was published in the literature [10]. According to the data, the typical phenotype includes a pear-shaped nose (with a large ridge and a broad tip, and an elongated philtrum), a thin, upper vermillion giving the appearance of a horizontal smile, and large prominent ears. Other frequently reported findings are maxillary prognathism with mandibular hypoplasia [1].

Trichologic findings may vary. These include fine, sparse, or brittle hair, diffuse alopecia, or severe hypotrichosis. In severe cases, baldness can be observed. Scalp hair growth might be slower than in healthy individuals and may reach only a limited length [1]. Also, recession of the frontotemporal hairline is common, while the occipital hairline is occasionally receded $[11,12]$. Sparse hair on the lateral third of the eyebrows is also a common finding [1].

Musculoskeletal abnormalities include brachydactyly, deviation of the phalanges, and a typical radiographic finding of cone-shaped epiphyses [7, 10]. Hip malformations, low stature, nail dystrophy, and "racket" nails are other common findings $[10,13,14]$.

LAS is a benign and self-limiting condition caused by abnormalities in the hair's anchoring mechanism. It might be sporadic or inherited in an autosomal dominant pattern. It predominantly affects young girls between 2 and 6 years of age, who usually present a reduced hair 
Fig. 3. Clinical and trichoscopy findings of the father. a Similar phenotype as the daughter. b Hair thinning and black granular rectangular structures on trichoscopy. c Racket nails on the thumbs, and widening of the 4 th and 5 th fingers. d Brachydactyly, as well as deviation of the phalanges on both feet.

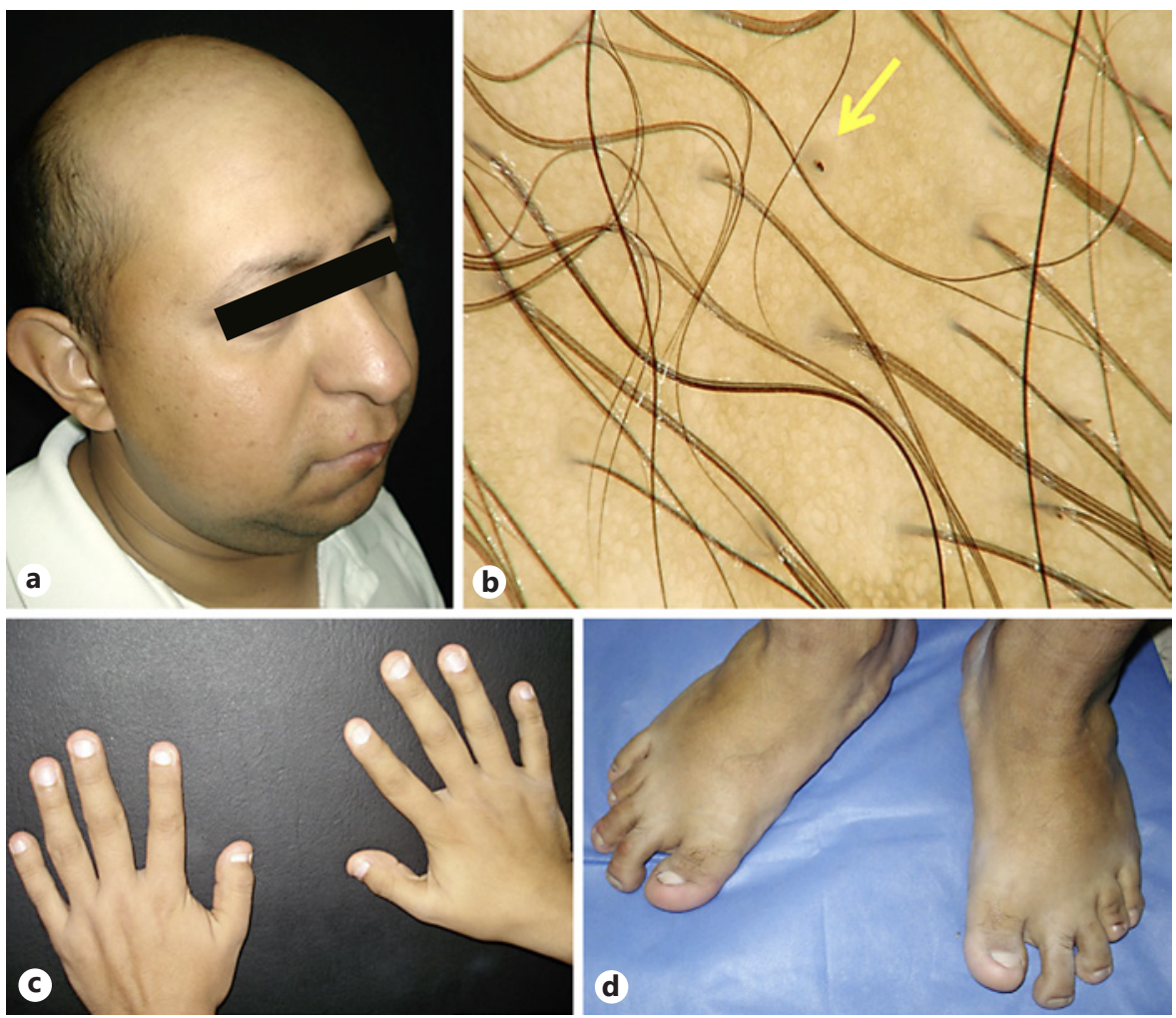

length, as well as easily pluckable hair without pain [8]. Parents usually complain of the lack of hair growth in their children. Physical examination shows sparse, fine hair, and diffuse or patchy alopecia $[8,15]$.

Even though the precise mechanism of LAS is unknown, it is thought to be caused by a premature keratinization of the inner root sheath (IRS), resulting in impaired adhesion between the cuticle of the IRS and the cuticle of the hair shaft (a finding that was observed in our patient's biopsy) [8]. The trichogram of LAS shows more than $70 \%$ of anagen hairs, devoid of the inner and outer root sheaths. Ruffling of the cuticle and misshapen anagen bulbs in an acute angle to the shaft are also typical findings [15].

LAS has been associated with other entities such as coloboma, Noonan syndrome, hypohidrotic ectodermal dysplasia, TRPS, nail-patella syndrome, and neurofibromatosis, among others [8].

Rectangular black granular structures are a unique feature of LAS, observed in up to $71 \%$ of patients [16]. Pathology demonstrated that these structures most likely correspond to the rectangular shape of an anagen follicle, which becomes "rapidly empty" in the course of LAS.

Trichorhinophalangeal Syndrome and Loose Anagen Syndrome

\section{Conclusions}

To our knowledge, this is the first report that documents the association of TRPS and LAS in a family. We also propose the correlation of the black rectangular trichoscopic structures with the pathology of empty anagen follicles. More reports are needed for verification of this information.

\section{Acknowledgements}

We would like to thank the patient and her family for kindly cooperating.

\section{Statement of Ethics}

The parents of the patient provided their informed consent to publish the case (including the publication of images).

\section{Disclosure Statement}

The authors have no conflicts of interest to declare.

Skin Appendage Disord 2020;6:162-167 DOI: $10.1159 / 000506524$ 


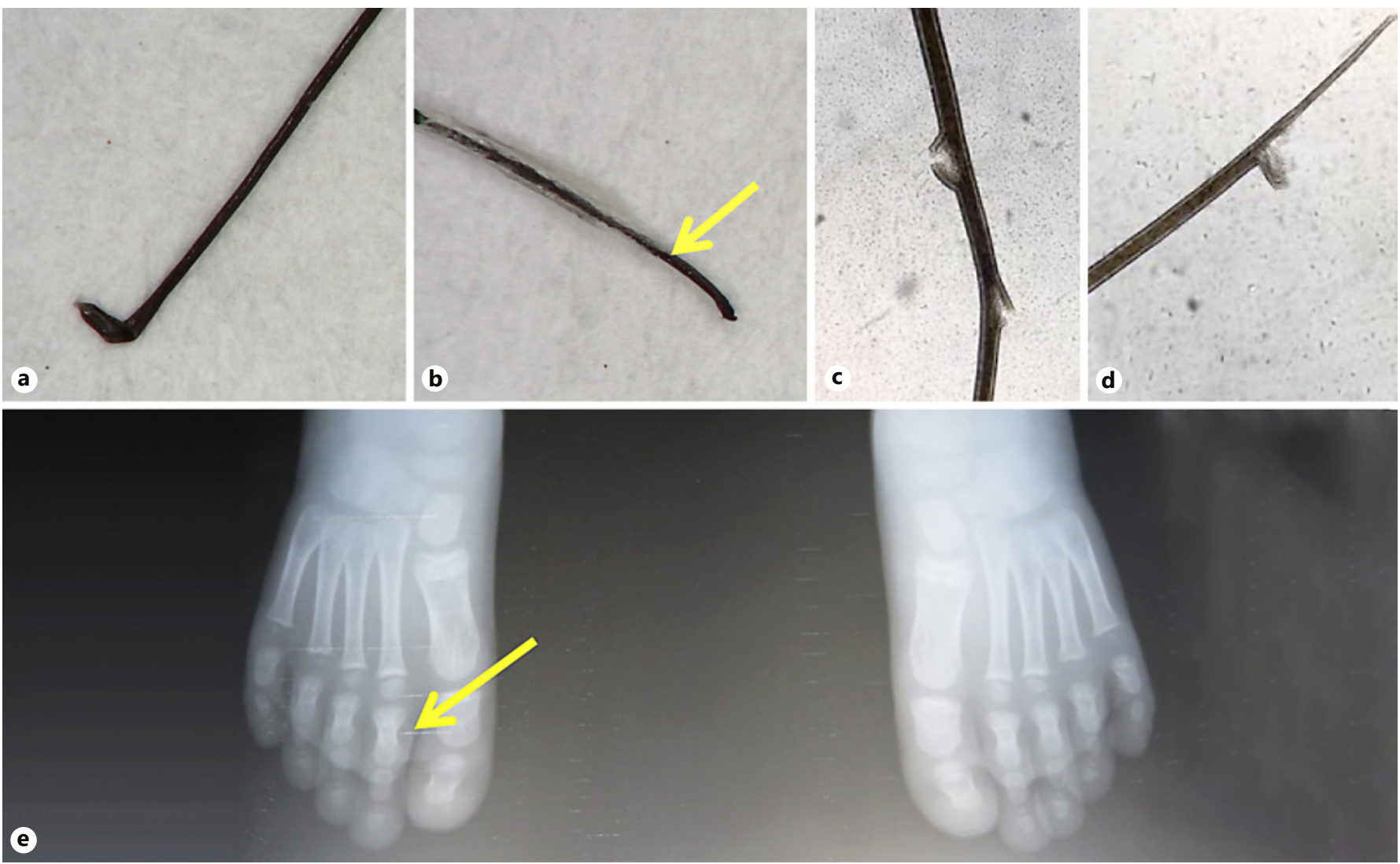

Fig. 4. Trichoscopy and radiographic findings. a Anagen bulb at an acute angle to the shaft. b Disruption of the hair sheath. c, d Distal hair fractures. e Cone-shaped epiphyses of the second fingers of both feet.

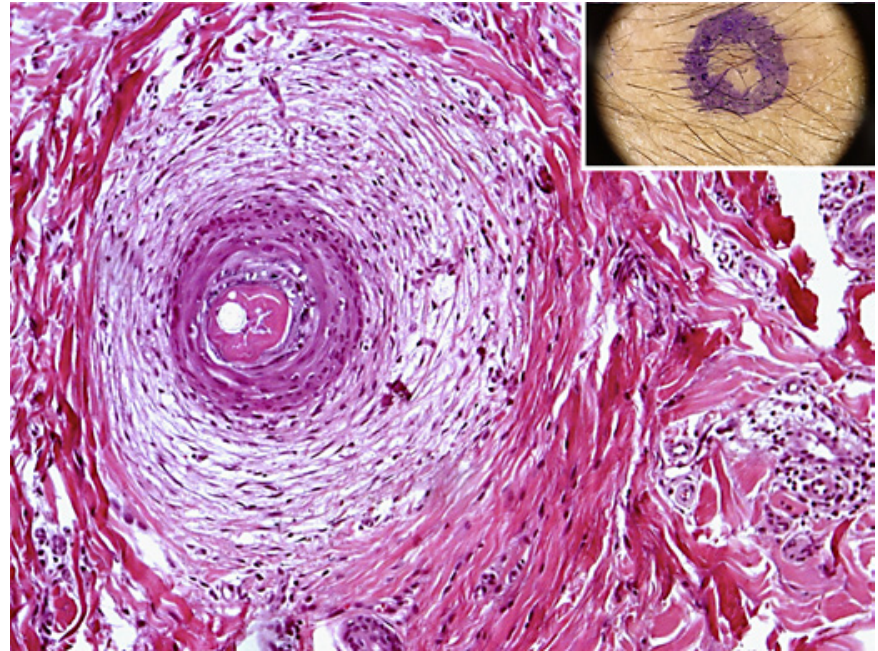

Fig. 5. Histopathology of the trichoscopic black granular rectangular structures observed in the father's scalp showed lamellar fibroplasia around anagen follicles, as well as desquamation and rupture of the inner hair root sheath.

\section{Funding Sources}

There are no sources of funding in relation to this study.

\section{Author Contributions}

S.C.G.-G.: acquisition, analysis of data, draft preparation. M.E.H.-R.: acquisition, analysis of data, draft preparation. M.G.-F. and N.E.V.-H.: acquisition and analysis of data. C.M.: acquisition and analysis of data, pathologic correlation. A.T.: acquisition, analysis, and interpretation of data; revision of the manuscript. S.C.-A.: acquisition of data, draft preparation. J.O.-C.: analysis and interpretation of data; revision of the manuscript. A.V.-M.: acquisition and analysis of data; draft preparation; revision of the manuscript. All authors gave their final approval of the report. 


\section{References}

1 Seitz CS, Lüdecke HJ, Wagner N, Bröcker EB, Hamm H. Trichorhinophalangeal syndrome type I: clinical and molecular characterization of 3 members of a family and 1 sporadic case. Arch Dermatol. 2001 Nov;137(11): 1437-42.

2 Gonzalez-Huerta LM, Cuevas-Covarrubias SA, Messina-Baas OM. Tricho-rhino-phalangeal type I syndrome and mental retardation: identification of a novel mutation in the TRPS1 gene. J Dermatol Sci. 2007 Oct;48(1): 61-3.

3 Langer LO Jr, Krassikoff N, Laxova R, ScheerWilliams M, Lutter LD, Gorlin RJ, et al. The tricho-rhino-phalangeal syndrome with exostoses (or Langer-Giedion syndrome): four additional patients without mental retardation and review of the literature. Am J Med Genet. 1984 Sep;19(1):81-112.

4 Niikawa N, Kamei T, Opitz JM. The SugioKajii syndrome, proposed tricho-rhino-phalangeal syndrome type III. Am J Med Genet. 1986 Aug;24(4):759-60.
5 Lüdecke HJ, Schaper J, Meinecke P, Momeni P, Gross S, Hirche H, et al.; von Holtum D. Genotypic and phenotypic spectrum in tricho-rhino-phalangeal syndrome types I and III. Am J Hum Genet. 2001 Jan;68(1):81-91.

6 Camacho FM, Tosti A. Montagna Tricología. Enfermedades del folículo pilosebáceo. Volume 1. Madrid, Spain: Libros Princeps. Biblioteca Aula Médica; 2013.

7 Giedion A, Burdea M, Fruchter Z, Meloni T, Trosc V. Autosomal-dominant transmission of the tricho-rhino-phalangeal syndrome. Report of 4 unrelated families, review of 60 cases. Helv Paediatr Acta. 1973 Jul;28(3):249-59.

8 Dhurat RP, Deshpande DJ. Loose anagen hair syndrome. Int J Trichology. 2010 Jul;2(2):96100.

9 Cantatore-Francis JL, Orlow SJ. Practical guidelines for evaluation of loose anagen hair syndrome. Arch Dermatol. 2009 Oct;145(10): $1123-8$.

10 Maas SM, Shaw AC, Bikker H, Lüdecke HJ, van der Tuin K, Badura-Stronka M, et al. Phenotype and genotype in 103 patients with tricho-rhino-phalangeal syndrome. Eur J Med Genet. 2015 May;58(5):279-92.
11 Camacho F, Armijo M, Naranjo R, Dulanto F. Le syndrome Tricho-Rhino-Phalangien (Giedion). Ann Dermatol Venereol. 1978; 105(1):17-21.

12 Lalević-Vasić BM, Nikolić MM, Polić DJ. Étude des cheveux: du syndrome trichorhinophalangien type I. Ann Dermatol Venereol. 1994;121(9):618-22.

13 Carrington PR, Chen H, Altick JA. Trichorhinophalangeal syndrome, type I. J Am Acad Dermatol. 1994 Aug;31(2 Pt 2):331-6.

14 Yáñez S, Hernández-Vicente I, Armijo M. Trichorhinophalangeal syndrome. Int J Dermatol. 1992 Oct;31(10):706-9.

15 Abdel-Raouf H, El-Din WH, Awad SS, Esmat A, Al-Khiat M, Abdel-Wahab H, et al. Loose anagen hair syndrome in children of Upper Egypt. J Cosmet Dermatol. 2009 Jun;8(2): 103-7.

16 Rakowska A, Zadurska M, Czuwara J, Warszawik-Hendzel O, Kurzeja M, Maj M, et al. Trichoscopy findings in loose anagen hair syndrome: rectangular granular structures and solitary yellow dots. J Dermatol Case Rep. 2015 Mar;9(1):1-5. 